\title{
A PARTICIPAÇÃO DOS ENFERMEIROS NOS PROGRAMAS DE APERFEIÇOAMENTO*
}

\author{
Luciane Lúcio Pereira** \\ Paulina Kurcgant***
}

\begin{abstract}
RESUMO - O estudo busca o conhecimento das facilidades e dificuldades identificadas pelos enfermeiros para a participação em programas de aperfeiçoamento, oferecidas tanto pela instituição em que trabalham como por outras instituições. O estudo busca, também, a verificação da importância conferida por esses profissionais aos programas e fomecer subsídios, com base nos resultados obtidos, para o planejamento de programas de aperfeiçoamento para a enfermeira. A presente pesquisa encontra- se em fase de coleta de dados, com a adoção da técnica de entrevista realizadas com a utilização de um formulário composto de perguntas semi-estruturadas. As informações obtidas serão trabalhadas numa proposta quantitativa e qualitativa de análise.
\end{abstract}

ABSTRACT - The purpose of this study is to identify reasons why nurses do or do not take part in improvement programs offered either by their place of work or by other institutions. It also aims at the importance given to these programs. This data will provide important subsidies for the planning of nursing improvement programs. Data are being compiled by use of a questionnaire with per-structured questions followed by an interview. A quantitative and qulitative analysis will be dealt based on this information.

\section{INTRODUÇÃO}

O desenvolvimento dos recursos humanos tem sido um aspecto considerado extremamente importante e essencial para o sucesso de uma empresa. Esta preocupação é evidenciada no último século na Teoria "y" de McGREGOR ${ }^{13}$ e na mais recente teoria " $z$ " de OUCHI. ${ }^{16}$

A Teoria "y", segundo seus pressupostos, entende os indivíduos como sendo responsáveis e comprometidos com o trabalho, o apoio e estímulo da instituição como elemento fundamental para o bom desempenho humano.

A Teoria " $\mathrm{z}$ " dá grande ênf ase à administração de pessoal e parte de pressupostos que, para o sucesso da empresa, é essencial o processo decisório ser consensual e participativo. Com esta intenção cooperativa, dispensa recursos para o desenvolvimento de habilidades interpessoais necessárias à decisão grupal efetiva.
A necessidade de aperfeiçoamento profissional tem sido reforçada pelo avanço tecnológico e pelas constantes mudanças sociais que geram no indivíduo a necessidade de buscar, adquirir, rever e atualizar seus conhecimentos.

Dessa maneira, o desenvolvimento do indivíduo tem um caráter de continuidade, independentemente do tempo de exercício profissional em determinada atividade ou instituição.

Ainda em face das conquistas sociais da nova constituição, cabe às empresas um repensar do sistema de recursos humanos, buscando tomá-lo mais ágil e eficiente. $^{8}$

Também na área da saúde é ressaltado por vários autores como GONÇALVES ${ }^{9}$, LEITE $^{11}$, MARCONDES $^{12}$, NUNEZ ${ }^{15}$, SILVA $^{17}$ e SILVA ${ }^{18}$ a importância da elaboração de programas de desenvolvimento profissional para a real consecução dos objetivos organizacionais.

* Nota Prévia

* Enfermeira. Auxiliar de Ensino do Departamento de Orientação Profisisonal da Escola de Enfermagem da Universidade de São Paulo / Lotada na disciplina Administração Aplicada à Enfermagem.

*** Enfermeira. Professor Assistente Doutor do Departamento de Orientação Profisisonal da Escola de Enfermagem da Universidade de São Paulo / Lotada na disciplina Administração Aplicada à Enfermagem. 
Segundo MEJÍA, ${ }^{14}$ os profissionais de saúde, ao completarem sua formação inicial, estão capacitados apenas para começar e têm caminhos apontados para continuar um processo de educação durante toda a vida profissional. Sem esse processo contínuo, a competência decresce progressivamente, como conseqüência de uma dinâmica influenciada pela incongruência da formação inicial com a realidade da prática, devido à experiência que tanto pode agnupar e consolidar ações e condutas pertinentes, quanto induzirem a hábitos nem sempre válidos, pela falta de memória e pelas transformações trazidas por novas tecnologias, mudanças sociais e epidemiológicas, troca de emprego e modificações no ambiente de trabalho.

Segundo MARCONDES, ${ }^{12}$ o emprego de estratégias de desenvolvimento de recursos humanos, na área da saúde, teve seu início nos anos 60 , tendo sido progressivamente adotado, principalmente, pelas instituições hospitalares.

O hospital, enquanto sistema assistencial de saúde, que interage com o ambiente externo, se diferencia como organização complexa, caracterizada por uma dinâmica acelerada de tecnologia de conhecimentos e procedimentos, fortemente compromissada com a qualidade. Esses aspectos tornam imperativa a necessidade de pessoal qualificado.

A enf ermagem, atuante no sistema de saúde, também evidencia a necessidade de propostas que levam a um maior desenvolvimento profissional de seu pessoal. Os enfermeiros buscam novos conhecimentos, na tentativa de suprir espaços vazios deixados pela formação básica no curso de graduação e, de uma forma mais ampla, buscam tornar a enfermagem uma ciência pela formulação de um corpo próprio de conhecimentos.

Em 1979 a Associação Brasileira de Enfermagem $^{2}$ realizou o $1^{\circ}$ Seminário de Educação Continuada, considerando a importância da aquisição progressiva de competência profissional na enfermagem. Esta competência se revela na auferição de melhor qualidade na assistência de enfermagem. Com base nestes considerandos, este seminário recomendou às instituições de saúde a mobilização de esforços para a elaboração de programas dirigidos para o aperfeiçoamento dos profissionais participantes da assistência de enfermagem.

Também, o Ministério da Saúde, ${ }^{5}$, na articulação de propostas para a viabilização do Sistema Único de Saúde, conside ra fundamental a elaboração de programas de capacitação permanente, visando a atualização técnica e científica, principalmente de enfermeiras, por considerá-las elemento estratégico na melhoria da qualidade da assistência prestada.

Os estudos do COFEN/ABEn, ${ }^{4}$ sobre Força do Trabalho em Enfermagem, indicam que $81,2 \%$ dos enfermeiros no Brasil consideram o oferecimento regular de cursos de aperfeiçoamento e atualização de pessoal pela instituição onde trabalham, como de suma importância para a eficiência e satisfação no trabalho.

Entretanto, a prática tem mostrado que embora os enfermeiros solicitem programas de aperfeiçoamento, quando estes são of erecidos, não contam coma participa;cão dos solicitantes e, algumas vezes, quando estes participam, não demonstram aproveitamento, ficando os resultados muito aquém do esperado. Isso, muitas vezes, ocorre mesmo quando os enfermeiros são consultados quanto às suas necessidades e interesses, ou mesmo quando são operacionalizados programas dentro do horário de trabalho, com um gasto fincanceiro mínimo para o indivíduo.

$\mathrm{ALSPACH}^{1}$ refere que o desenvolvimento de programas educacionais em hospitais envolve substancial investimento de tempo, dinheiro e recursos humanos. Este aspecto acrescido ao desgaste dos indivíduos envolvidos na fase de planejamento, execução e avaliação dos programas torna fundamental que seja avaliado o nível de participação da clientela à qual o curso se destina, bem como à consecução dos resultados esperados.

Pela literatura intemacional pode-se verificar uma crescente preocupação com aspectos relativos à validade dos programas de aperfeiçoamento, como podemos verificar em estudos de CERVERO, ${ }^{6} \mathrm{COX},{ }^{7}$ DUQUETTE.. ${ }^{8}$

Na literatura nacional, o trabalho de SILVA ${ }^{18}$ apresenta uma proposta de programas de aperfeiçoamento de pessoal, baseada na experiência, por ela vivenciada, junto a um setor de Educação Continuada em enfermagem. Essa autora relata, como dificuldades sentidas no desenvolvimento dos programas, no que diz respeito ao funcionário, a existência de outros interesses que competem com seu tempo disponível; o pouco reconhecimento da instituição pela participação do funcionário na programação; ameaça psicológica à auto-estima pois, de certa forma, ao participar desses programas o funcionário reconhece suas limitações; resistência à modificação de hábitos de métodos de trabalho; falta de consciência da necessidade de aprender. 
No convívio com enfermeiras resgata-se, em suas falas, explicações para a contradição entre o discurso e a prática. Isto pode ser apreendido quando os enfermeiros referem que, não são liberados para freqüentar o curso por falta de pessoal; há falta de reconhecimento, por parte da chefia imediata, da necessidade e da importância de participarem de programas de aperfeiçoamento; falta de tempo para cursos for a do horário de trabalho; falta de recursos financeiros que viabilizem a participação; os programas não atendem às reais expectativas individuais e são pouco relacionados à prática diária.

Pela literatura e pelo vivencial na educação continuada em enfermagem, pode-se aceitar o aperfeiçoamento de pessoal como sendo "atividades que propiciem ao indivíduo oportunidades de aprof undamento, atualização e ampliação de conhecimento profissionais". Estas atividades podem ser realizadas tanto dentro da instituição, através de reuniões científicas, palestras e cursos elaborados, ministrados ou coordenados pela área de Educação Continuada, como fora dela, através de visitas a outras instituições, cursos de atualização, extensão universitária e pós-graduação e participação em eventos como Congressos, Encontros, Jomadas, etc. ${ }^{11,17}$

Faz-se necessário também, o entendimento do significado de aperfeiçoamento, uma vez que várias modalidades de programas têm sido propostas e implementadas com diferentes denominações. Porém, mais importante que a terminologia é a crença de que existe uma correlação positiva entre qualidade de assistência e processo de desenvolvimento integral do homem. Isso, por sua vez, deverá estar relacionado à sua proposta de educação continuada prevista numa política de pessoál que contemple esse aspecto. ${ }^{11}$

Assim, pretende-se desenvolver uma pesquisa que objetiva conhecer as facilidades e dificuldades identificadas pelos enf ermeiros para participarem dos programas de aperfeiçoamento of erecidos pela instituição em que trabalha e por outras instituições; verificar a importância conferida por eles a esses programas e subsidia com base nos resultados obtidos, 0 planejamento de programas de aperfeiçoamento para enfermeiros.

\section{METODOLOGIA}

O presente estudo está tendo por base a análise de dados obtidos junto a uma amostra de enfermeiras que, no período de janeiro a julho de 1991, desempenhavam atividades profissionais em hospitais gerais do município de São Paulo, os quais desenvolvem programas de aperfeiçoamento para enfermeiras.

Os dados utilizados para a escolha desses hospitais tiveram como fonte as informações do Cadastro de Estabelecimentos de Saúde do centro de Documentação do Ministério da Saúde ${ }^{3}$ e o Cadastro de Estabelecimento de Saúde em Assistência Médica Sanitária do $\mathrm{IBGE}^{10}$

Pela compilação das informações das duas fontes chegou-se ao número total de hospitais. Seguindo orientação estatística, esses hospitais forma submetidos a um programa de amostragem seqüencial, por sorteio, na proporção de três para quinze, ou seja, de cada quinze hospitais foram sorteados três hospitais. Nesses hospitais foi verificada a existência, ou não, de programas de aperfeiçoamento para enfermeiras. Esse levantamento preliminar foi feito, por contato telefônico, junto às chefias de enfermagem dos hospitais.

De posse dessas informações, levantou-se o número de enfermeiras lotadas nas instituições que, comprovadamente, desenvolvam programas de aperfeiçoamento para enfermeiros. Dessa forma, chegouse ao número total de enfermeiros.

Com o objetivo de manter-se, na mostra de estudo, a representatividade dos diferentes hospitais gerais que desenvolvem programas para enfermeiras, optou-se pela amostragem estratificada, sendo os estratos representados pelos diferentes tipos de hospitais.

Pelo fato de se estabelecer, conforme orientação estatística, uma amostra constituída de $20 \%$ da população total em estudo, objetivou-se também igual representatividade de cada estrato. Assim, o número de enfermeiras que participam do estudo corresponde a $20 \%$ da população de cada estrato.

\section{PROCEDIMENTO}

Optou-se pela adoção da técnica de entrevistas, devido à relação de interação que ela propicia, além de permitir correções, esclarecimentos e adaptações que facilitem a captação das informações desejadas.

Na coleta de dados está sendo utilizado um formulário para a entrevista das enfermeiras. No formulário estão contidos dados pessoais de caracterização do entrevistado e perguntas semi-estruturadas relativas à sua participação em programas de aperfeiçoamento oferecidos pela instituição onde trabalha e por outras instituições.

Para o tratamento dos dados, optar-se-á pela análise quantitativa e qualitativa das informações obtidas. 


\section{REFERÊNCIAS BIBLIOGRÁFICAS}

1 ALPACH, J. The educational process in critical care nursing. Missouri, EUA, The C.V. Mosby Company, 1982.

2 ASSOCIAÇÃO BRASILEIRA DE ENFERMAGEM, $1^{\circ} \mathrm{Se}-$ minário de Educação Continuada em Enfermagem. Rev. Bars. Enf., Brasília, 33:8-101, 1980.

3 BRASIL, Cadastro de Estabeleciementos de Saude. Brasil, 1985. Brasília, centro de Documentação do Ministério da Saúde, 1986. v. 1.

4 BRASIL. CONSELHO FEDERALDE ENFERMAGEM. ASSOCIAÇÃO BRASILEIRA DE ENFERMAGEM. Força de trabalho em enfermagem; $O$ exercicio da enfermagem nas instituições de saude do Brasil 1982/1983. Rio de Janeiro:1986, v. 1.

5 BRASIL. MINISTÉRIO DA SAÚDE. SECRETARIA DE MODERNIZAÇO ADMINISTRATIVA E RECURSOS HUMANOS. A Educação Continuada de Enfermeira no SUS, Brasilia, Centro de Documentação doMinistério da Saude, 1990.

6 CERVERO, R.M. Continuing Professional Education and Behavioral Change: A Model for Research and Evaluation. The Journal of Continuing Education in Nursing. 16(3):85-88, 1985.

7 COX, C.L., BAKER, M.G. Evaluation: The key to accountability in continuing education in nursing. The Journal of Continuing Education in Nursing. 12(1) 11-19, 1981.

8 DUQUETE, A. et al. Reason for nonparticipation in continuing nursing education. Research in Nursing Education. Research in Nursing/Health. 11:119-209, 1988.
9 GONÇALVES, E.L. Administração de recursos humanos nas instituições de saúde. São Paulo: Pioneira.

10 INSTITUTO BRASILEIRO DE GEOGRAFIA E ESTATÍSTICA (IBGE). Cadastro de Estabelecimentos de Saúde: Assistncia Médico-Sanitária. 2. ed. Rio de Janeiro: IBGE/Departamento de Estatistica e Indicadores Sociais, 1988. v.5.

11 LEITE, M.M.J., PEREIRA, L.L. Educação Continuada de Enfermagem. In:KURCGANT, P. Administração do Serviço de Enfermagem. São Paulo, E.P.U. (no prelo).

12 MARCONDES, R.S. Treinamento de pessoal em hospitais. Rev. Bras. Enf. São Paulo, $6(10)$ 436-40,1978.

13 McGREGOR, D. Motivação e Liderança. São Paulo: Brasiliense, 1973.

14 MEJÍA, A. Educación Continua. Educación Médica y salud. 20 (1) 43-71, 1986.

15 NUNEZ, R.S. Educação em serviço: fator de desenvolvimento de recursos humanos em enfermagem. Rev. Bras. Enf. Brasilia, 33(1):54-81, 1980.

16 OUCHI, W.G. Teoria Z: Como as empresas podem enfrentar o desafio japonês. São Paulo: Nobel, 1986.

17 SILVA, A.L.C. Caracterização das formas de progresso para competência continuada em enf ermagem. Rev. Bras. Enf. Brasilia, 33:453-61, 1980.

18 SILVA, M.J.P. de, PEREIRA, L.L., BENKO, M.A. Educação continuada: estratégia para o desenvolvimento de pessoal de enf ermagem. Rio de Janeiro: Marques - Saraiva/São Paulo, EDUSP, 1989. p. 75-973. 